Chapman University

Chapman University Digital Commons

Psychology Faculty Articles and Research

Psychology

2009

\title{
Maturation of the Human Fetal Startle Response: Evidence for Sex-Specific Maturation of the Human Fetus
}

\author{
Claudia Buss \\ University of California - Irvine \\ Elyssia Poggi Davis \\ University of California - Irvine \\ Quetzal A. Class \\ Indiana University \\ Matt Gierczak \\ University of California - Irvine \\ Carol Pattillo \\ University of California - Irvine \\ See next page for additional authors
}

Follow this and additional works at: http://digitalcommons.chapman.edu/psychology_articles

Part of the Cardiology Commons, Maternal and Child Health Commons, and the Obstetrics and Gynecology Commons

\section{Recommended Citation}

Buss C*, Davis EP, Class QA, Gierczak M, Patillo C, Glynn LM \& Sandman CA (2009). Maturation of the human fetal startle response: Evidence for sex-specific maturation of the human fetus. Early Human Development, 85, 633-638.

DOI:10.1016/j.earlhumdev.2009.08.001 


\section{Maturation of the Human Fetal Startle Response: Evidence for Sex- Specific Maturation of the Human Fetus}

\section{Comments}

NOTICE: this is the author's version of a work that was accepted for publication in Early Human Development. Changes resulting from the publishing process, such as peer review, editing, corrections, structural formatting, and other quality control mechanisms may not be reflected in this document. Changes may have been made to this work since it was submitted for publication. A definitive version was subsequently published in Early Human Development, volume 85, in 2009. DOI:10.1016/j.earlhumdev.2009.08.001

The Creative Commons license below applies only to this version of the article.

\section{Creative Commons License}

\section{(c) (1) $\Theta \Theta$}

This work is licensed under a Creative Commons Attribution-Noncommercial-No Derivative Works 4.0 License.

\section{Copyright}

Elsevier

\section{Authors}

Claudia Buss, Elyssia Poggi Davis, Quetzal A. Class, Matt Gierczak, Carol Pattillo, Laura M. Glynn, and Curt A. Sandman 


\title{
Maturation of the human fetal startle response: Evidence for sex- specific maturation of the human fetus ${ }^{1}$
}

\author{
Claudia Buss ${ }^{a}$, Elysia Poggi Davis ${ }^{a}, b$, Quetzal A. Class $^{c}$, Matt Gierczak $^{a}$, Carol Pattillo $^{a}$, \\ Laura M. Glynn ${ }^{a}, d$, and Curt A. Sandman ${ }^{a}$ \\ aDepartment of Psychiatry and Human Behavior, University of California, Irvine, 333 The City Blvd. \\ W, Suite 1200, Orange, CA 92868 \\ ${ }^{b}$ Department of Pediatrics, University of California, Irvine, Irvine, CA 92697-5020 \\ 'Department of Psychological and Brain Sciences, Indiana University, Bloomington, IN \\ dDepartment of Psychology, Chapman University, Orange, CA 92866
}

\begin{abstract}
Despite the evidence for early fetal experience exerting programming influences on later neurological development and health risk, very few prospective studies of human fetal behavior have been reported. In a prospective longitudinal study, fetal nervous system maturation was serially assessed by monitoring fetal heart rate (FHR) responses to vibroacoustic stimulation (VAS) in 191 maternal/ fetal dyads. Responses were not detected at 26 weeks gestational age (GA). Sex-specific, agecharacteristic changes in the FHR response to VAS were observed by 31 weeks' GA. Males showed larger responses and continued to exhibit maturational changes until 37 weeks' GA, females however, presented with a mature FHR startle response by 31 weeks' GA. The results indicate that there are different rates of maturation in the male and female fetus that may have implications for sex-specific programming influences.
\end{abstract}

\section{Introduction}

Despite acknowledgement of the critical role the prenatal period plays for an individual's health outcome, little effort has been invested in studying human fetal behavior and its consequences. This knowledge gap recently has been recognized by the National Academy of Sciences, that criticized that although much attention has been paid to obtaining accurate obstetric estimates of gestational age, the need for more methods of assessing fetal maturity has been underestimated [1].

Normal development of the central nervous system depends on complex, dynamic mechanisms with multiple spatial and temporal components during gestation. In the prenatal period, neurons proliferate, migrate, and aggregate, providing the "hardware" of the developing brain. In fact,

\footnotetext{
${ }^{1}$ Supported by awards to CAS from the NINDS (NS-41298) and NICHD (HD-51852)

(C) 2009 Elsevier Ireland Ltd. All rights reserved.

Corresponding author: Curt A. Sandman, Department of Psychiatry and Human Behavior, University of California, Irvine, 333 City Drive West, Suite 1200, Orange California 92868, casandma@uci.edu.

Conflict of interest statement: None declared.

Publisher's Disclaimer: This is a PDF file of an unedited manuscript that has been accepted for publication. As a service to our customers we are providing this early version of the manuscript. The manuscript will undergo copyediting, typesetting, and review of the resulting proof before it is published in its final citable form. Please note that during the production process errors may be discovered which could affect the content, and all legal disclaimers that apply to the journal pertain.
} 
neuronal proliferation before birth is estimated at an average rate of 250,000 per minute [2]. It is undeniable that the antenatal period is critical for central nervous system development, but still it is not included in campaigns aimed to optimize child development [3]. So, although it is well accepted that parturition does not represent a significant demarcation in neural development, relatively little effort has been invested in understanding the functional development of the human fetus.

It has been argued [4] that observations of fetal behaviors and behavioral changes provide a noninvasive method of determining and assessing brain functioning. There is growing appreciation that fetal neurobehaviors reflect the developing nervous system [4-7] and the possibility of establishing developmental milestones for the fetus has been proposed [8].

Therefore, monitoring fetal behavior provides an opportunity to assess fetal functional nervous system development, as suggested by studies focusing on normally developing as well as at risk fetuses [5,7,9-11]. Antenatal maturation is a function of advancing central and autonomic control [12]. As gestation progresses, resting fetal heart rate (FHR) declines [13-16], variability increases and there is tighter coupling between fetal movement and heart rate $[5,10,17,18]$. There is evidence that these are stable patterns by the second half of gestation [3,6,19-22]. Less is known about functional or evoked measures, although stability for some response measures has been reported later in gestation [19,23].

There is evidence for antenatal origins of infant characteristics. Continuity has been reported between fetal heart rate and movement patterns and infant mental and motor development [24-29], infant temperament [19,21,29,30] and infant autonomic function [3,31]. This suggests an opportunity for early detection of impaired development. There is substantial evidence from animal and human studies that suggests there are different developmental consequences resulting from a variety of prenatal environmental exposures based on the offspring's sex [e.g. $32,33,34]$. This may be either a reflection of sex-specific susceptibility to environmental insults or it may reflect different neurodevelopmental trajectories for males and females that result in sex-specific developmental intervals of maximum susceptibility to environmental exposures. There is some evidence for sex-specific fetal behavior [35,36] but to date no studies have focused on sex-specific fetal maturation. A better understanding of fetal developmental trajectories will provide information about sensitive developmental periods/ time windows when environmental exposures may be most influential in changing the developmental path.

Understanding development of fetal behavior is a critical first step to determine the transition between fetal and postnatal life. This prospective longitudinal study of 191 fetuses, describes the sex-specific trajectories of FHR maturation reflected in patterns of responses to, and recovery from, stimulation.

\section{Methods}

\section{Participants}

One hundred and ninety-one mother-fetus dyads were recruited and consented prior to their $16^{\text {th }}$ week of gestation. Women gave informed consent for all aspects of the protocol, which was approved by the Institutional Review Board for protection of human subjects. All pregnancies were singleton intrauterine pregnancies in English-speaking women at least 18 years of age. Comprehensive interviews obtaining medical and psychosocial information were performed at consistent intervals over the course of pregnancy. Maternal medical records were reviewed by a research nurse to assess prenatal medical history and birth outcome. Participants reported not using tobacco, alcohol, or other drugs during pregnancy and did not present with uterine or cervical abnormalities. Women were excluded if they had any condition potentially associated with dysregulated neuroendocrine function such as endocrine, hepatic or renal 
disorders or if they used corticosteroid medications. Obstetric risk was defined as the presence of certain risk factors and medical conditions in the index pregnancy, including hypertension, preeclampsia, vascular risk factors (e.g., vascular bleeding, placentia abruptio, anemia, placentia brevia), diabetes (gestational diabetes, diabetes type 1 and 2), and severe infection during pregnancy (chlamydia, syphillis, toxoplasmosis, bacterial vaginosis). Given our exclusion criteria, the vast majority of our study sample (74\%) was at low-risk for adverse pregnancy outcomes.

Maternal demographic information is summarized in Table 1. Pregnant women attended up to three study visits for assessment of fetal maturity, with $48 \%$ of the women attending 3 visits, $28 \%$ attending 2 visits and $24 \%$ attending 1 visit (average of $2.3 \pm 0.78$ visits, Table 1 ).

Gestational age (GA) at each assessment period was determined by last menstrual period and confirmed by an ultrasound conducted before 20 weeks' GA. Fetal monitoring was performed between 10:00 a.m. and 5:30 p.m. Time of testing did not significantly differ between the three pregnancy visits $\left(\mathrm{F}_{(1.96,296.7)}=0.2, \mathrm{p}=0.75\right)$.

\section{Fetal Assessments}

At each assessment, mothers reclined in a semi-fowlers position (5-10 degree tilt) on a standard, padded examination table and the vibroacoustic stimulator (VAS) was placed on the mother's abdomen above the fetal head, as determined by ultrasonography. Pure-tone music was presented to the mother through headphones to mask extraneous noise and the acoustic component of stimulation. Fetal assessment began with a 15 minute baseline (resting) recording of fetal heart rate (FHR) followed by a 1-second administration of the startling VAS (72dB, $75 \mathrm{~Hz}+10 \%$ harmonics ranging from $20-9000 \mathrm{~Hz}$, EAL Model 146, Corometric Medical System, $C T, U S A)$ on the mother's abdomen. The fetal monitoring period concluded with 5 minutes of FHR recording to assess the fetal VAS startle response.

The instruments used in this study were designed to quantify FHR variation due to ex utero stimulation [7,37]. Transabdominal transducers were positioned until a robust FHR signal was reliably detected. All fetal information and uterine contractions were quantified by a Toitu MT-430 ultrasound fetal monitor that measured frequency shifts in a weak ultra-sound beam projected on the fetus by an ultrasonic head. Data from the fetal monitor were digitized at $2 \mathrm{kHz}$ sampling rate with Active II, (Biosemi Instrumentation) and transferred automatically to an off-line server for analysis.

During the observation period, no uterine contractions occurred. Integrity of the FHR data was assured with customized software that included a viewer for examination of each tracing to scan for artifacts. An interpolation routine was applied, if needed, with a 1-second resolution to each tracing to correct 5-10 second epochs with missing data. Each tracing was examined by a trained observer and a judgment was made about the validity of interpolation. If a segment of the data resulted in unacceptable interpolations (the interval was greater than ten seconds or the estimate did not match the valid data points), that section of the data was omitted from the analyses. All analyses were performed using FHR data at 1-second resolution. FHR data for 120 seconds pre VAS and 30 seconds post VAS were used for analyses. To rule out any impact of preparation of VAS administration on baseline FHR levels, the interval 180-60 seconds preceding the VAS was chosen for analyses. Average FHR at baseline and in response to the VAS over the course of the three pregnancy visits are shown in figure 1.

\section{Plan of Analysis}

Hierarchical linear modeling (HLM) growth curve analyses [38,39] were used to describe the change in the trajectories of FHR responses over the course of gestation. HLM, when used with repeated measures, treats the data in a hierarchical fashion with observations nested within 
persons. This approach allows variance to be modeled at multiple levels and provides several advantages over ordinary least squares (OLS) regression [39], including (i) assessment of within-subject variability over time; (ii) estimates of goodness of fit in modeling in which the most reliable data are given greater statistical weight, and (iii) robust estimates of missing values for the repeated dependent measure. Cases with complete data are weighted more heavily, but all cases are included in the estimation of effects. Finally, HLM uses precise measures of timing (gestational age at assessment) of data collection rather than nominal estimates of assessment intervals. The advantage of a repeated measures approach such as the one used in this study is that the statistical power is improved not only by the number of participants, but also by the large number of observations obtained for each fetus [40].

A 3-level model was set up to evaluate age-related changes in FHR to ex utero stimulation with time in reference to VAS administration (1-second intervals from baseline to 30 seconds post VAS) modeled on level 1, gestational age at each of the three assessments on level 2, and significant time invariant covariates modeled on level 3. The HLM analysis proceeded in three major steps [41].

\section{Step 1- Modeling fetal heart rate patterns $\mathbf{3 0}$ seconds post VAS administration}

-Level 1 captured parameters that change within an individual and within an assessment period. Quadratic modeling, which captures the initial increase in FHR and subsequent decline of the FHR response, proved to be superior to linear modeling (p's< 0.001 ). The quadratic solution produces three coefficients for comparison: (1) the mean level differences or the intercepts at each second post VAS administration, (2) the instantaneous rate of change (linear slope) at each second post VAS administration (3) the overall acceleration (shape) of the curve. Centering time at each second post VAS stimulation allowed testing of the age-related changes for different segments of the response curve. The two time parameters and the intercept were included as random factors since they are known to have substantial variability across individuals.

The level 1 model predicting FHR (where $i$ represents the subject and $j$ represents the repeated assessments over gestation and $k$ represents the repeated data collection at each assessment) is:

$$
\mathrm{FHR}_{\mathrm{ijk}}=\pi_{0}+\pi_{1} * \mathrm{Time}_{\mathrm{ijk}}+\pi_{2} * \mathrm{Time}_{\mathrm{ijk}}^{2}+\mathrm{e}_{\mathrm{ijk}}
$$

\section{Step 2- Associations between gestational age and fetal heart rate response} patterns to VAS stimulation-Level 2 captured changes in FHR patterns across gestational ages. Exact gestational age at each assessment was modeled (centered at mean gestational age at first visit, 26 weeks' GA) to capture change in FHR patterns across pregnancy. Thus, on level 2 interactions between gestational age at assessment and the level $1 \pi$-coefficients were assessed.

$$
\begin{aligned}
& \pi_{0}=\beta_{00}+\beta_{01} *\left(\mathrm{GA}_{\mathrm{ij}}\right)+\mathrm{r}_{0 \mathrm{ij}} \\
& \pi_{1}=\beta_{10}+\beta_{11} *\left(\mathrm{GA}_{\mathrm{ij}}\right)+\mathrm{r}_{1 \mathrm{ij}} \\
& \pi_{2}=\beta_{20}+\beta_{21} *\left(\mathrm{GA}_{\mathrm{ij}}\right)+\mathrm{r}_{2 \mathrm{ij}}
\end{aligned}
$$

Step 3- Association between time invariant covariates and fetal heart rate
patterns post VAS stimulation-Person-level factors, variables that did not change from
one assessment to the next, were introduced at level 3. Fetal sex and the following covariates 
were tested for their impact on fetal heart rate: parity, maternal age, obstetric risk and race/ ethnicity. Thus, on level 3, interactions between person-level factors and the level $2 \beta$ coefficients were assessed.

$$
\begin{aligned}
& \beta_{00}=\gamma_{000}+\gamma_{001}\left(\text { fetal } \operatorname{sex}_{\mathrm{i}}\right)+\mathrm{u}_{00} \\
& \beta_{01}=\gamma_{010}+\gamma_{011}\left(\text { fetal } \operatorname{sex}_{\mathrm{i}}\right) \\
& \beta_{02}=\gamma_{020}+\gamma_{021}\left(\text { fetal } \text { sex }_{i}\right) \\
& \beta_{10}=\gamma_{100}+\gamma_{101}\left(\text { fetal } \operatorname{sex}_{\mathbf{i}}\right)+\mathrm{u}_{10} \\
& \beta_{11}=\gamma_{110}+\gamma_{111}\left(\text { fetal } \operatorname{sex}_{\mathrm{i}}\right) \\
& \beta_{12}=\gamma_{120}+\gamma_{121}\left(\text { fetal } \operatorname{sex}_{\mathrm{i}}\right) \\
& \beta_{20}=\gamma_{200}+\gamma_{201}\left(\text { fetal } \operatorname{sex}_{\mathbf{i}}\right)+\mathrm{u}_{20} \\
& \beta_{21}=\gamma_{210}+\gamma_{211}\left(\text { fetal } \text { sex }_{\mathrm{i}}\right) \\
& \beta_{22}=\gamma_{220}+\gamma_{221}\left(\text { fetal } \operatorname{sex}_{\mathbf{i}}\right)
\end{aligned}
$$

\section{Results}

\section{Fetal heart rate trajectories over the course of gestation}

Modeling fetal heart rate from average baseline to 30 seconds post VAS administration indicated that the age-related decline in average baseline FHR was significant $\left(\beta_{01}=-0.4, \mathrm{p}<\right.$ 0.001 ) and that FHR decreased by 0.4 beats per minute with each week of gestation. Moreover, with each week of gestation, fetuses exhibited a steeper gradient of increase in response to the stimulus $\left(\beta_{11}\right.$ 's $=0.05$, p's $\left.=0.001 ; 0.05\right)$. The overall slope of the curve became significantly steeper with increasing age $\left(\beta_{21}=-0.002, \mathrm{p}<0.001\right)$, both during acceleration (response) and deceleration (recovery) in reaction to the startling stimulus. Among the potential covariates evaluated, only fetal sex had a significant impact on the age-related changes in fetal heart rate, indicated by the interaction between gestational age at assessment and fetal sex on the overall shape of the response curve $\left(\beta_{21}=-0.002, p=0.02\right)$. Baseline FHR was not affected by fetal $\operatorname{sex}(\mathrm{p}=0.88)$.

Because baseline FHR decreased over the course of gestation, the absolute FHR response to the VAS was modeled by changes (deltas) in FHR from individual average baseline, calculated for each subject by subtracting the average baseline FHR from every 1 second post startle stimulus for a 30-second interval. This yielded a better representation of the FHR response to VAS. Modeling delta values from baseline (set to 0 for all age groups) to 30 seconds after VAS administration supported the findings reported for the raw FHR data. Older fetuses exhibited a steeper increase in response to the stimulus $\left(\beta_{11}\right.$ 's $=0.03, p=0.05$, Figure 2$)$. The overall slope of the curve did not significantly change with increasing age $\left(\beta_{21}=-0.0008, \mathrm{p}=0.11\right.$, Figure 2). Testing the same covariates listed above supported fetal sex as the only variable that affected the developmental trajectory of the FHR response as indicated by the interaction between GA at assessment and fetal sex on the overall shape of the curve $\left(\beta_{21}=-0.002, p=\right.$ $0.01)$.

For each fetus the average of FHR deltas from 1 to 30 seconds post VAS was calculated and follow-up t-tests were performed to test sex-differences in the magnitude of the response at each assessment. Higher means of FHR deltas from baseline over 30 seconds post stimulation indicated a higher magnitude of the FHR response in male than in female fetuses at the second and third assessments $\left(\mathrm{T} 1: \mathrm{t}_{(136)}=0.97, \mathrm{p}=0.34, \mathrm{~T} 2: \mathrm{t}_{(153)}=2.12, \mathrm{p}=0.04, \mathrm{~T} 3: \mathrm{t}_{(141)}=2.16, \mathrm{p}=\right.$ $0.03)$. All subsequent analyses of absolute FHR increase from baseline were conducted for male and female fetuses separately. 


\section{Age-related changes in male fetuses}

Modeling delta values from baseline to 30 seconds after VAS administration in male fetuses reflected the model that included males and females and indicated that older male fetuses exhibited the steepest increase in response to the stimulus $\left(\beta_{11}=0.08, \mathrm{p}<0.001\right)$. In addition, the overall shape of the curve (acceleration) changed significantly with increasing age $\left(\beta_{21}=\right.$ $-0.003, p<0.001$, Figure 3a). Because there were highly significant differences in FHR between the three ages, separate models were run comparing FHR responses at 26 with 31 weeks' GA as well as FHR responses at 31 with 36 weeks' GA.

26 weeks old fetuses versus $\mathbf{3 1}$ weeks old fetuses-Male fetuses at 31 weeks' GA displayed significantly larger FHR responses than 26 week-old fetuses from 4 to 29 seconds after the stimulus ( $\beta_{01}$ 's $=0.65$ to 1.66 , $p$ 's $\left.<0.05\right)$. Older fetuses exhibited a steeper increase from the initiation of the stimulus continuously to 14 seconds after the stimulus $\left(\beta_{11}\right.$ 's $=0.03$ to 0.19 , p's $<0.05$ ) resulting in a larger FHR response. From 20 seconds after stimulation to the end of the assessment period, FHR decreased significantly in the 31 week-old fetuses $\left(\beta_{11}\right.$ 's $=-0.04$ to -0.15 , p's $\left.<0.05\right)$. The significant deceleration in FHR in the older fetuses resulted in non-significant intercept differences between the younger and older fetuses at 30 seconds after the VAS $\left(\beta_{01}=0.58, p=0.14\right)$, reflecting recovery from the response in the 31 week-old fetuses. Finally, the overall shape of the curve differed significantly based on gestational age $\left(\beta_{21}=-0.006, p<0.001\right.$, Figure 3a). These results indicate that male fetuses respond to and recover from stimulation by 31 weeks' GA but not at 26 weeks' GA.

31 weeks old fetuses versus $\mathbf{3 7}$ weeks old fetuses-There were no significant differences after stimulation in the intercepts ( $p$ 's $>0.10$ ), the magnitude of the response ( $p$ 's $>$ $0.05)$ or the overall shape of the curve $(p=0.72$, Figure $3 a)$ between the male fetuses at 31 weeks' GA and at 37 weeks' GA. Older fetuses, however, exhibited a significantly faster recovery in response to the stimulus. The differences in recovery emerged in the linear slope at 9 seconds after stimulus administration and this decrease from peak continued to be significantly steeper in the older fetuses until 18 seconds after stimulation $\left(\beta_{11}\right.$ 's $=-0.03$ to $-0.4, p$ 's $<0.05$, Figure $3 a)$. The steeper decrease in the older fetuses suggested faster FHR decline from the initial increase to stimulation and reflects more complete recovery. These results indicate that male fetuses initially respond similarly to stimulation at 31 and 37 weeks' GA, but that the older fetus exhibits a pattern of more rapid recovery than the fetus at 31 weeks' GA.

\section{Age-related changes in female fetuses}

Modeling delta values from baseline to 30 seconds after VAS administration in female fetuses also reflected the general model and indicated that older female fetuses exhibited a steeper increase in response to the stimulus $\left(\beta_{11}=0.03, \mathrm{p}<0.05\right)$. Unlike males, the overall shape of the curve did not change significantly with increasing age ( $p=0.11$, Figure $3 b)$. To better understand the maturational pattern of the FHR startle response in females, separate models were run comparing FHR responses at 26 with 31 weeks' GA as well as FHR responses at 31 with 36 weeks' GA.

26 weeks old fetuses versus 31 weeks old fetuses-Compared with the youngest fetuses, fetuses at 31 weeks' GA had significantly larger FHR responses beginning four seconds after the startling stimulus that continued to be elevated up to 27 seconds post VAS ( $\beta_{01}$ 's= 0.50 to 1.05 , p's $<0.05$ ). This response in the 31 week-old fetuses was accompanied by a steeper increase in the FHR slope immediately after the stimulus and continued for 12 seconds $\left(\beta_{11}\right.$ 's $=0.03$ to 0.12 , p's $\left.<0.05\right)$. After reaching the peak response, FHR decreased significantly in the 31 week-old fetuses from 22 seconds after stimulation to the end of the assessment period $\left(\beta_{11}\right.$ 's $=-0.04$ to $-0.11, \mathrm{p}$ 's $\left.<0.05\right)$. This significant deceleration in FHR in the older fetuses 
resulted in non-significant intercept differences between the younger and older fetuses from $28-30$ seconds post VAS ( $\beta_{01}$ 's $=0.50$ to 0.3 , p's $>0.11$ ), indicating recovery. This pattern was confirmed by the significant differences in the overall shape of the response curve $\left(\beta_{21}=-0.004\right.$, $p=0.002$, Figure $3 b$ ). Therefore, these results indicate that female fetuses at 31 weeks' GA, but not at 26 weeks' GA, respond to, and recover from, a startling stimulus.

31 weeks old fetuses versus $\mathbf{3 7}$ weeks old fetuses-There were no differences in response to the startling stimulus in female fetuses between 31 weeks' and 37 weeks' GA. No differences were detected between the two age groups in the intercepts (p's>0.30), the agerelated changes in the slopes of the response pattern (p's>0.14) or the overall shape of the curve ( $\mathrm{p}=0.15$, Figure $3 b)$. These results indicate that in the female fetus, the response to a startling stimulus at 31 weeks' GA does not differ from the response at 37 weeks' GA, indicating a mature response at 31 weeks' GA.

\section{Discussion}

The developmental trajectory of the FHR startle response in the human fetus develops into a robust response by 31 weeks' gestation for both male and female fetuses. This developmental schedule is consistent with reports from previous studies [42-44]. There were, however, significant differences between male and female fetuses in response magnitude and in the pattern of maturation. The primary sex difference in FHR, apparent at 31 and 37 weeks' GA, was the larger response in the male fetuses. Despite the fact that the baseline levels and the pattern of response after stimulation were similar, the males presented with a nearly two-fold larger FHR response than the females. Moreover, and perhaps most interesting, females did not exhibit different response patterns at 31 and 37 weeks' GA. Males, however, exhibited slower recovery patterns at 31 weeks' GA compared with their pattern at 37 weeks' GA. These results provide the first evidence of differences between male and female fetuses in response to a startling stimulus and evidence for subtle but significant differences in the trajectory of maturation which may contribute to sex-specific time windows when the developing fetus is vulnerable to programming influences. This conclusion is consistent with a recent observation from our group that prenatal exposure to maternal stress hormones has different consequences for neuromuscular development in male and female newborns. In early and mid gestation, higher maternal cortisol and CRH concentrations were associated with lower neurodevelopmental scores in males whereas in late gestation, higher cortisol concentrations predicted higher neurodevelopmental scores in females [32].

The results from the current study provide a guide for understanding the expected functional capability of the human fetus following a simple stimulus that elicits a very basic response. As such, these findings extend results from a small group of studies that have defined fetal neurobehavioral aptitude with the long term goal of understanding the transition to infant, child and adult life [3,28-31]. The current findings emphasize the importance of studying the fetal response pattern rather than a single characteristic of the response (e.g. magnitude reflected by the peak response), to elucidate the functional maturation of the human fetus and to provide a richer profile for examination of the transition to life outside the womb. To fully capture the maturational trajectories, the initiation or slope of the response, the peak, and the latency to peak response, the pattern of recovery and the shape of the response curve all contributed to defining the fetal patterns.

There is a vast literature on sex differences in behavioral, neurological and developmental outcomes, but there are very few studies on sex differences in human fetal function. Most available reports are on baseline measures and are consistent with our observations that baseline FHR does not differ between male and female fetuses [e.g. 45,46]. There is one longitudinal study [35] and one study with a single fetal assessment [36] that reported higher baseline 
variability in male fetuses. The current study is the only report of sex differences in the human fetus in response to stimulation. Studies focusing on FHR responses as a measure of maturation either have not tested or reported sex differences [42-44].

Measures of human fetal responding are accepted indicators of fetal maturity [42] that reflect the development and integrity of neural pathways through the cerebral cortex, midbrain, brainstem, vagus nerve, and the cardiac conduction system [18]. It is assumed that the behavior of the fetus is a reflection of reflexive brainstem activities that are produced in the absence of forebrain-mediated affective or cognitive processing, like thinking, reasoning, understanding or true emotionality [47]. Hepper [4] advocated developing a detailed description of fetal behavior that would result in a template of "normal" fetal behavior and reflect neural system functioning. This approach would allow assessment of proximal programming influences on the human fetus and advance the scientific study of early human development. Without an accepted understanding of the normal course of human fetal functional maturation, it is difficult to assess the significance of potential influences on development. We have reported that there may be both optimal [48] and detrimental [37,49] endocrine influences on fetal behavior. Others have reported that maternal prenatal psychosocial depression, stress and anxiety can influence fetal behavior [23,29,50-52]. These are important observations but conclusions across studies are tenuous at best because there is not a common metric or measure that allows a comparison with a pattern of normal fetal behavior.

The great majority of evidence that supports the fetal programming hypothesis is retrospective and relies on gross measures of early experience such as gestational age at birth and birth weight. Despite the growing acceptance that early fetal experience exerts programming influences on postnatal neurological development and on health risk and the fact that the retrospective studies supporting this conclusion rely on gross phenotypes that are at best indirect measures of programming influences, very few prospective studies of human fetal behavior have been reported. In addition to the possibility that the study of fetal behavior has not progressed because it has been judged as insignificant, it is equally plausible to conclude that studies of the human fetus are simply too difficult to conduct. The evidence is compelling that the consequences of fetal exposures and experience for brain and behavioral development are not insignificant. The study of the human fetus, however, does present several unique challenges. Methods of measurement and procedures for exploring the functional capability of the fetus coupled with the perceived fragility of the maternal/fetal dyad may have been barriers for the study of the human fetus. The study reported here and those conducted by others indicate that the psychology of the human fetus is not only important, but clearly feasible. The availability of references for normal fetal development offers the opportunity to detect the influence of environmental exposures during fetal life that may be accompanied by changes in the trajectory of fetal maturation.

A vast majority of neurodevelopmental disorders originate during gestation [53] and patterns of illness vary by sex [54]. Therefore, describing prenatal sex-specific maturation is a promising first step in detecting and predicting child development, and then ultimately preventing the development of adverse health outcomes such as obesity, diabetes and neurobehavioral problems. Extending the developmental perspective to fetal life and understanding the normal trajectory of fetal nervous system development will allow detection of deviations at a time when interventions may be most effective.

\section{Acknowledgments}

This research was supported by National Institute of Health grants HD51852 and NS41298 to CAS. 


\section{References}

1. IOM. Preterm Birth: Causes, Consequences, and Prevention. The National Academy of Science Press; 2007.

2. Cowan WM. The development of the brain. Scientific American 1979 Sep;241(3):113-33. [PubMed: 493917]

3. DiPietro JA, Costigan KA, Pressman EK, Doussard-Roosevelt JA. Antenatal origins of individual differences in heart rate. Developmental psychobiology 2000 Dec;37(4):221-8. [PubMed: 11084603]

4. Hepper, PG. The behavior of the fetus as an indicator of neural functioning. In: Lecanuet, J-P.; Fifer, WP.; Krasnegor, NA.; Smotherman, WP., editors. Fetal Development: A psychobiological perspective. Hillsdale: Lawrence Erlbaum Associates; 1995. p. 405-17.

5. Dipietro JA, Irizarry RA, Hawkins M, Costigan KA, Pressman EK. Cross-correlation of fetal cardiac and somatic activity as an indicator of antenatal neural development. American journal of obstetrics and gynecology 2001 Dec;185(6):1421-8. [PubMed: 11744919]

6. Nijhuis IJ, ten Hof J, Nijhuis JG, Mulder EJ, Narayan H, Taylor DJ, et al. Temporal organization of fetal behavior from 24-weeks gestation onwards in normal and complicated pregnancies.

Developmental psychobiology 1999 May;34(4):257-68. [PubMed: 10331150]

7. Sandman CA, Wadhwa P, Hetrick W, Porto M, Peeke HV. Human fetal heart rate dishabituation between thirty and thirty-two weeks gestation. Child development 1997 Dec;68(6):1031-40. [PubMed: 9418223]

8. Birnholz JC, Stephens JC, Faria M. Fetal movement patterns: a possible means of defining neurologic developmental milestones in utero. Ajr 1978 Mar;130(3):537-40. [PubMed: 415565]

9. Hepper PG. Human fetal behaviour and maternal cocaine use: a longitudinal study. Neurotoxicology 1995 Spring;16(1):139-43. [PubMed: 7603634]

10. Nijhuis IJ, ten Hof J. Development of fetal heart rate and behavior: indirect measures to assess the fetal nervous system. European journal of obstetrics, gynecology, and reproductive biology 1999 Nov;87(1):1-2.

11. Nijhuis JG. Fetal behavior. Neurobiology of aging 2003 May-Jun;24(Suppl 1):S41-6. [PubMed: 12829106]discussion S7-9, S51-2

12. DiPietro JA. Neurobehavioral assessment before birth. Mental retardation and developmental disabilities research reviews 2005;11(1):4-13. [PubMed: 15856447]

13. Martin CB Jr. Regulation of the fetal heart rate and genesis of FHR patterns. Seminars in perinatology 1978 Apr;2(2):131-46. [PubMed: 366763]

14. Patrick J, Campbell K, Carmichael L, Probert C. Influence of maternal heart rate and gross fetal body movements on the daily pattern of fetal heart rate near term. American journal of obstetrics and gynecology 1982 Nov 1;144(5):533-8. [PubMed: 7137240]

15. James, D.; Pillai, M.; Smoleniec, J. Neurobehavioral development in the human fetus. In: Lecanuet, JP.; Fifer, WP.; Krasnegor, NA.; Smotherman, W., editors. Fetal development: a psychobiological perspective. Hillsdale: Lawrence Erlbaum Associates; 1995. p. 101-28.

16. DiPietro JA, Caulfield L, Costigan KA, Merialdi M, Nguyen RH, Zavaleta N, et al. Fetal neurobehavioral development: a tale of two cities. Developmental psychology 2004 May;40(3):44556. [PubMed: 15122969]

17. Pillai M, James D. Development of human fetal behavior: a review. Fetal diagnosis and therapy 1990;5 (1):15-32. [PubMed: 2101007]

18. Van Leeuwen P, Lange S, Bettermann H, Gronemeyer D, Hatzmann W. Fetal heart rate variability and complexity in the course of pregnancy. Early human development 1999 Apr;54(3):259-69. [PubMed: 10321792]

19. DiPietro JA, Hodgson DM, Costigan KA, Johnson TR. Fetal antecedents of infant temperament. Child development 1996 Oct;67(5):2568-83. [PubMed: 9022257]

20. Groome LJ, Singh KP, Bentz LS, Holland SB, Atterbury JL, Swiber MJ, et al. Temporal stability in the distribution of behavioral states for individual human fetuses. Early human development 1997 Apr 25;48(12):187-97. [PubMed: 9131319] 
21. DiPietro JA, Bornstein MH, Costigan KA, Pressman EK, Hahn CS, Painter K, et al. What does fetal movement predict about behavior during the first two years of life? Developmental psychobiology 2002 May;40(4):358-71. [PubMed: 12115294]

22. Ten Hof J, Nijhuis IJ, Mulder EJ, Nijhuis JG, Narayan H, Taylor DJ, et al. Longitudinal study of fetal body movements: nomograms, intrafetal consistency, and relationship with episodes of heart rate patterns a and B. Pediatr Res 2002 Oct;52(4):568-75. [PubMed: 12357052]

23. DiPietro JA, Costigan KA, Gurewitsch ED. Fetal response to induced maternal stress. Early human development 2003 Nov;74(2):125-38. [PubMed: 14580752]

24. Vlastos EJ, Tomlinson TM, Bildirici I, Sreenarasimhaiah S, Yusuf K, Sadovsky Y, et al. Fetal heart rate accelerations and the risk of cerebral lesions and poor neurodevelopmental outcome in very low birthweight neonates. American journal of perinatology 2007 Feb;24(2):83-8. [PubMed: 17260327]

25. Almli CR, Ball RH, Wheeler ME. Human fetal and neonatal movement patterns: Gender differences and fetal-to-neonatal continuity. Developmental psychobiology 2001 May;38(4):252-73. [PubMed: 11319731]

26. Groome LJ, Swiber MJ, Holland SB, Bentz LS, Atterbury JL, Trimm RF 3rd. Spontaneous motor activity in the perinatal infant before and after birth: stability in individual differences. Developmental psychobiology 1999 Jul;35(1):15-24. [PubMed: 10397892]

27. Leader LR, Baillie P, Martin B, Vermeulen E. The assessment and significance of habituation to a repeated stimulus by the human fetus. Early human development $1982 \operatorname{Dec} 6 ; 7(3): 211-9$. [PubMed: 7160332]

28. DiPietro JA, Bornstein MH, Hahn CS, Costigan K, Achy-Brou A. Fetal heart rate and variability: stability and prediction to developmental outcomes in early childhood. Child development 2007 NovDec;78(6):1788-98. [PubMed: 17988321]

29. Werner EA, Myers MM, Fifer WP, Cheng B, Fang Y, Allen R, et al. Prenatal predictors of infant temperament. Developmental psychobiology 2007 Jul;49(5):474-84. [PubMed: 17577231]

30. DiPietro JA, Costigan KA, Pressman EK. Fetal state concordance predicts infant state regulation. Early human development 2002 Jun;68(1):1-13. [PubMed: 12191524]

31. Kisilevsky BS, Muir DW. Human fetal and subsequent newborn responses to sound and vibration. Infant Behavior and Development 1991;14:1-26.

32. Ellman LM, Schetter CD, Hobel CJ, Chicz-Demet A, Glynn LM, Sandman CA. Timing of fetal exposure to stress hormones: effects on newborn physical and neuromuscular maturation. Developmental psychobiology 2008 Apr;50(3):232-41. [PubMed: 18335490]

33. Weinstock M. Gender Differences in the Effects of Prenatal Stress on Brain Development and Behaviour. Neurochem Res. 2007 Apr 4;

34. Weinberg J, Sliwowska JH, Lan N, Hellemans KG. Prenatal Alcohol Exposure: Foetal Programming, the Hypothalamic-Pituitary-Adrenal Axis and Sex Differences in Outcome. Journal of neuroendocrinology. 2008 Feb 8;

35. DiPietro JA, Costigan KA, Shupe AK, Pressman EK, Johnson TR. Fetal neurobehavioral development: associations with socioeconomic class and fetal sex. Developmental psychobiology 1998 Jul;33(1):79-91. [PubMed: 9664173]

36. Bernardes J, Goncalves H, Ayres-de-Campos D, Rocha AP. Linear and complex heart rate dynamics vary with sex in relation to fetal behavioural states. Early human development 2008 Jul;84(7):4339. [PubMed: 18248921]

37. Sandman CA, Glynn L, Wadhwa PD, Chicz-DeMet A, Porto M, Garite T. Maternal hypothalamicpituitary-adrenal disregulation during the third trimester influences human fetal responses. Developmental neuroscience 2003 Jan-Feb;25(1):41-9. [PubMed: 12876430]

38. Singer, J.; Willett, J., editors. Applied Longitudinal Data Analysis: Modeling Change and Event Occurrence. New York: Oxford University Press; 2003.

39. Raudenbush, SW.; Bryk, AS. Hierarchical Linear Models: Application and Data Analysis Methods. Thousand Oaks: Sage Publications; 2002.

40. Raudenbush SW, Liu X. Effect of study duration, frequency of observation, and sample size on power in studies of group differences in polynomial change. Psychological Methods 2001;6(4):387-401. [PubMed: 11778679] 
41. Adam EK. Transactions among adolescent trait and state emotion and diurnal and momentary cortisol activity in naturalistic settings. Psychoneuroendocrinology 2006 Jun;31(5):664-79. [PubMed: 16584847]

42. Kisilevsky BS, Muir DW, Low JA. Maturation of human fetal responses to vibroacoustic stimulation. Child development 1992 Dec;63(6):1497-508. [PubMed: 1446565]

43. Gagnon R, Hunse C, Patrick J. Fetal responses to vibratory acoustic stimulation: influence of basal heart rate. American journal of obstetrics and gynecology 1988 Oct;159(4):835-9. [PubMed: 3177532]

44. Gagnon R, Patrick J, Foreman J, West R. Stimulation of human fetuses with sound and vibration. American journal of obstetrics and gynecology 1986 Oct;155(4):848-51. [PubMed: 3766640]

45. Oguch O, Steer P. Gender does not affect fetal heart rate variation. British journal of obstetrics and gynaecology 1998 Dec;105(12):1312-4. [PubMed: 9883924]

46. McKenna DS, Ventolini G, Neiger R, Downing C. Gender-related differences in fetal heart rate during first trimester. Fetal diagnosis and therapy 2006;21(1):144-7. [PubMed: 16354993]

47. Joseph R. Fetal brain behavior and cognitive development. Developmental Review 2000;20:81-98.

48. Class QA, Buss C, Davis EP, Gierczak M, Pattillo C, Chicz-DeMet A, et al. Low levels of corticotropin-releasing hormone during early pregnancy are associated with precocious maturation of the human fetus. Developmental neuroscience 2008;30(6):419-26. [PubMed: 19127063]

49. Sandman CA, Wadhwa PD, Chicz-DeMet A, Dunkel-Schetter C, Porto M. Maternal stress, HPA activity, and fetal/infant outcome. Annals of the New York Academy of Sciences 1997;814:266-75. [PubMed: 9160976]

50. Monk C, Fifer WP, Myers MM, Sloan RP, Trien L, Hurtado A. Maternal stress responses and anxiety during pregnancy: effects on fetal heart rate. Developmental psychobiology 2000 Jan;36(1):67-77. [PubMed: 10607362]

51. Monk C, Myers MM, Sloan RP, Ellman LM, Fifer WP. Effects of women's stress-elicited physiological activity and chronic anxiety on fetal heart rate. J Dev Behav Pediatr 2003 Feb;24(1): 32-8. [PubMed: 12584483]

52. Allister L, Lester BM, Carr S, Liu J. The effects of maternal depression on fetal heart rate response to vibroacoustic stimulation. Developmental neuropsychology 2001;20(3):639-51. [PubMed: 12002098]

53. Connors SL, Levitt P, Matthews SG, Slotkin TA, Johnston MV, Kinney HC, et al. Fetal mechanisms in neurodevelopmental disorders. Pediatric neurology 2008 Mar;38(3):163-76. [PubMed: 18279750]

54. Holden, C. Science. Vol. 308. New York, NY: 2005 Jun 10. Sex and the suffering brain; p. 1574 


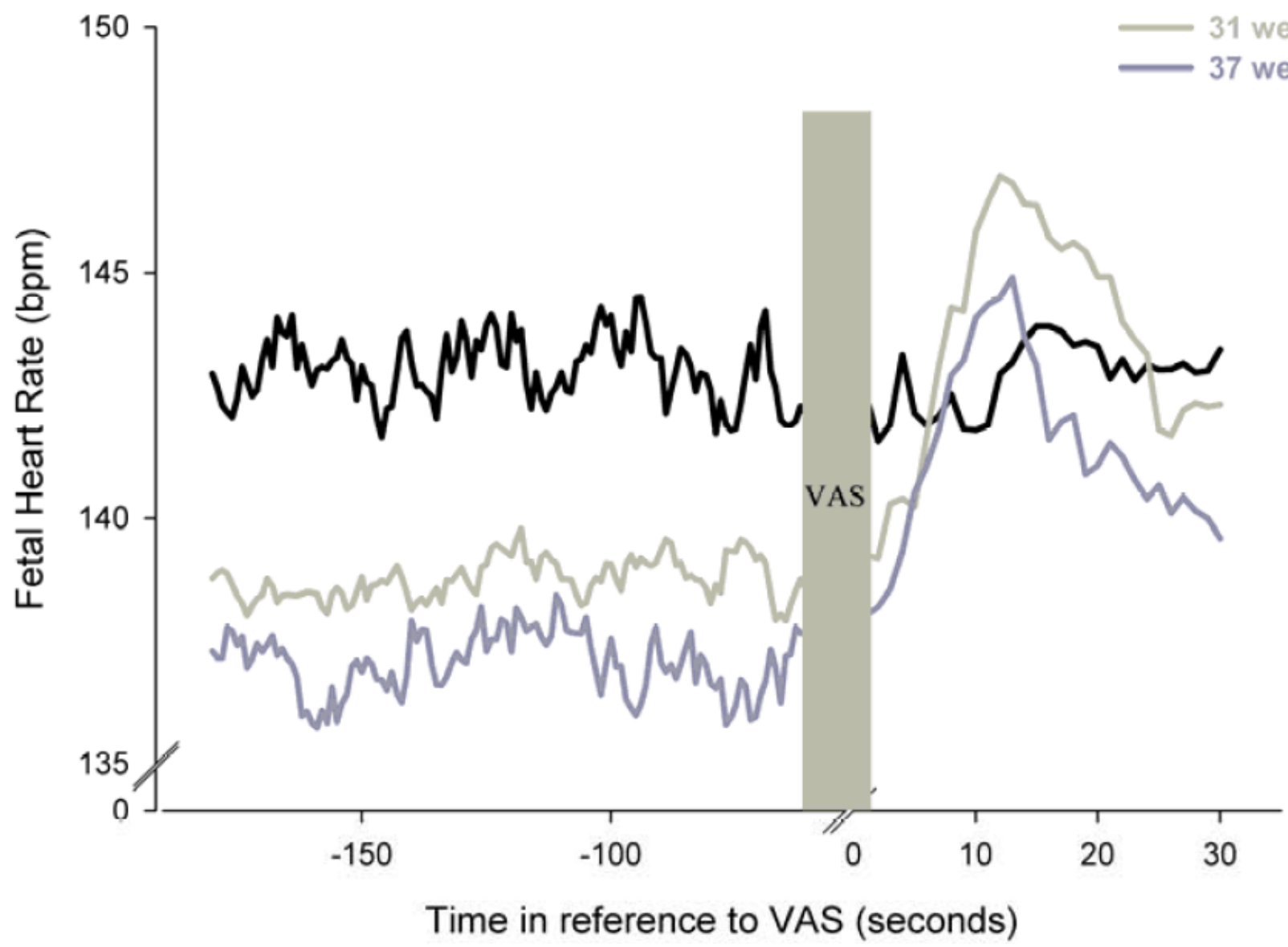

Figure 1.

Fetal heart rate during a 120 -second baseline period and 30 seconds after vibroacoustic stimulation at 26 weeks', 31 weeks', and 37 weeks' gestation. 


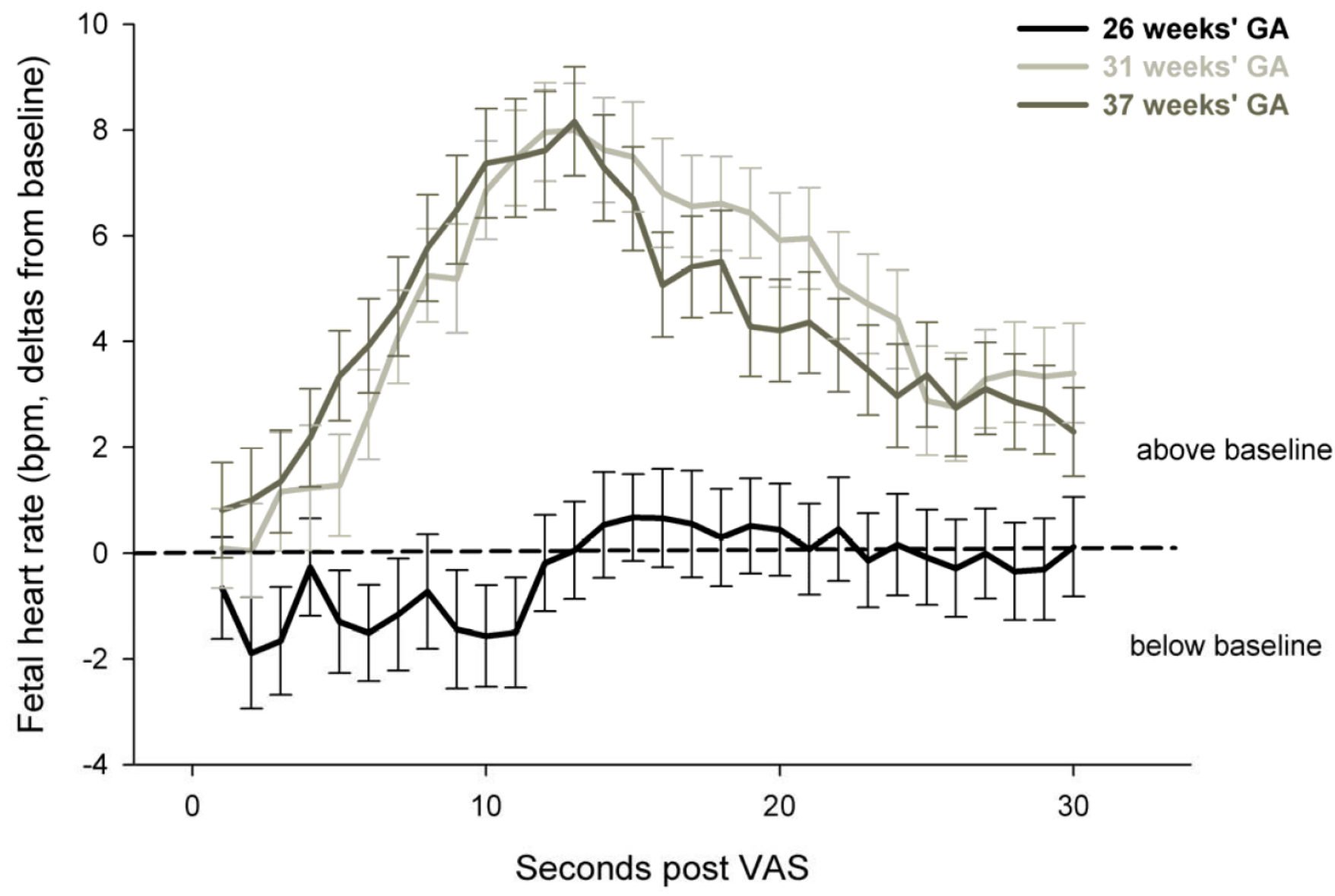

Figure 2.

Fetal heart rate changes (deltas) from average baseline to 30 seconds after vibroacoustic stimulation at 26 weeks', 31 weeks' and 37 weeks' gestation. Error bars represent standard error means. 
Male fetuses

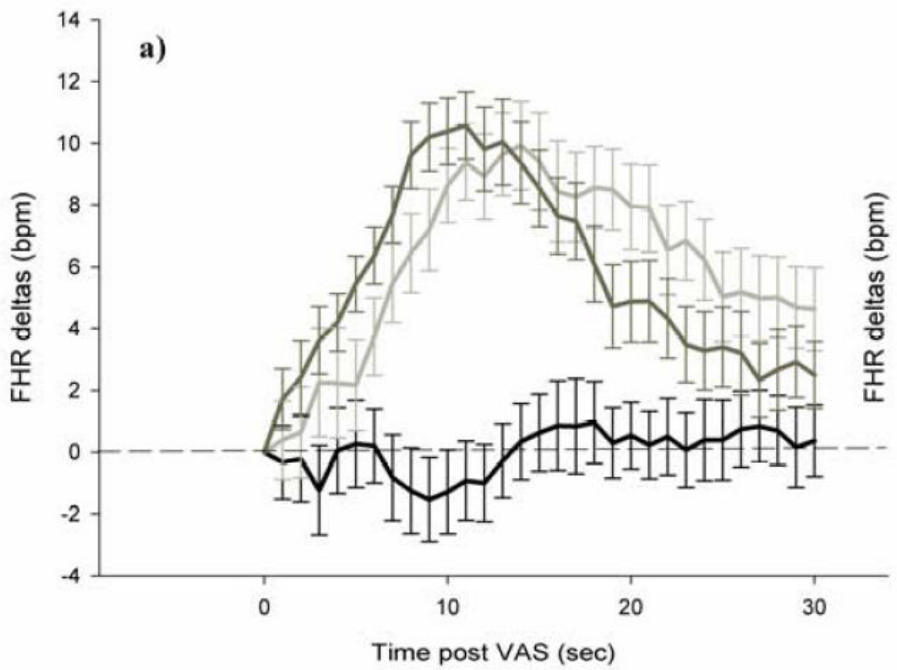

Female fetuses

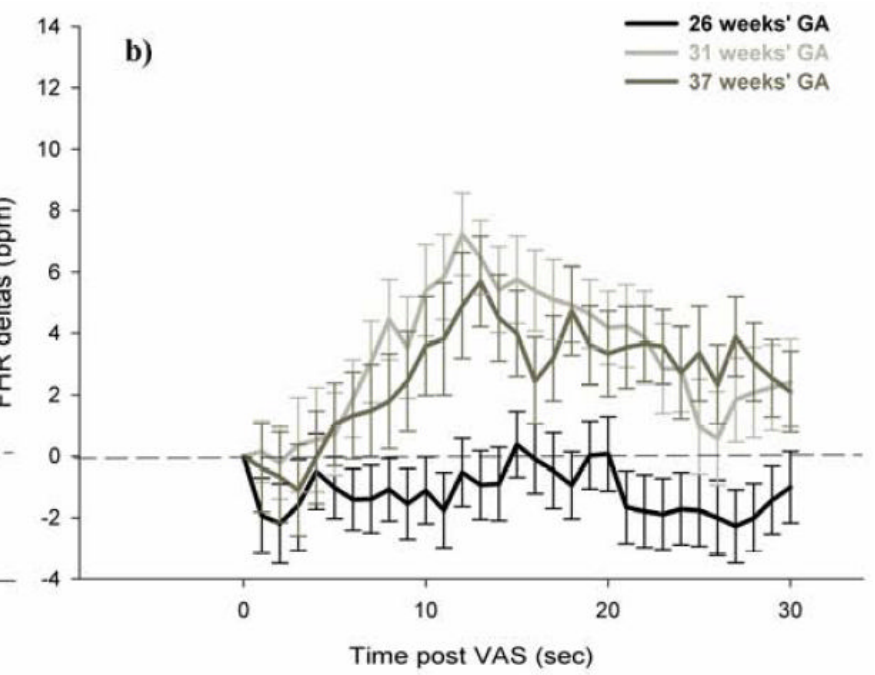

Figure 3.

Fetal heart rate changes (deltas) from average baseline to 30 seconds after vibroacoustic stimulation at 26 weeks', 31 weeks' and 37 weeks' gestation in male (a) and female (b) fetuses. Error bars represent standard error means. 
Table 1

Study sample descriptives

\begin{tabular}{lc}
\hline & Study Sample (N=191) \\
\hline Maternal age at delivery & $28.8(\mathrm{SD}=5.4)$ \\
Primiparous & $48 \%$ \\
Fetal sex & $51 \%$ \\
Male & $49 \%$ \\
Female & $97 \%$ \\
Education & $33 \%$ \\
High school or equivalent & \\
College graduate & $25 \%$ \\
Annual household income & $25 \%$ \\
$\$ 0$ to $\$ 30,000$ & $31 \%$ \\
$\$ 30,001$ and $\$ 60,000$ & $19 \%$ \\
$\$ 60,001$ and $\$ 100,000$ & $48 \%$ \\
Over $\$ 100,000$ & $27 \%$ \\
Race/Ethnicity & $9 \%$ \\
Non-Hispanic white & $\mathrm{N}=140$ \\
Hispanic & $\mathrm{N}=155$ \\
Asian & $\mathrm{N}=144$ \\
T1 $(25.5 \pm 0.8$ weeks' gestation) & \\
T2 $(30.8 \pm 0.7$ weeks' gestation) & \\
T3 (36.6 \pm 0.7 weeks' gestation) & \\
\hline
\end{tabular}

